\title{
Using anonymous probe-vehicle data for a performance indicator of bridge service
}

\author{
Andrew J. Bechtel \\ Department of Civil Engineering, The College of New Jersey, Ewing, NJ, \\ USA (corresponding author: bechtela@tcnj.edu) \\ (Orcid:0000-0002-2133-8305) \\ Thomas M. Brennan Jr. \\ Department of Civil Engineering, The College of New Jersey, Ewing, NJ, \\ USA (Orcid:0000-0003-2316-4983)
}

\author{
Kevin Gurski \\ Department of Civil Engineering, The College of New Jersey, Ewing, NJ, USA \\ Jessica Ansley \\ Department of Civil Engineering, The College of New Jersey, Ewing, NJ, USA
}

\begin{abstract}
Anonymous probe-vehicle data are being used to evaluate travel time reliability and congestion conditions along roadways. These telematics data are collected from commercial and private cell phones, global positioning system devices and on-board vehicles computers. In the last few years, these data have been incorporated into reports of highway and arterial systems to measure congestion conditions. For this paper, anonymous probe-vehicle data were used to calculate a congestion metric, at bridge locations in New Jersey, USA, based on aggregated yearly congestion hours. The congestion metric was then compared to the functionally obsolete (FO) performance designation defined by the US National Bridge Inventory (NBI). These FO bridges represent structures that, according to the NBI, theoretically cause congestion. The comparison showed that the FO designation did not indicate high levels of congestion and vice versa. Consequently, when the congestion metric was implemented in a rudimentary management strategy, it provided a clearer decision-making process over the current traffic carrying metric in the NBI. The results of this study show that the aggregated congestion metric can serve as a useful performance indicator for bridge structures at a regional level, and it can provide value when incorporated into a bridge asset management programme.
\end{abstract}

\author{
Notation \\ $\mathrm{C}_{\mathrm{Hs}} \quad$ congestion hours; number of 15 min bins whose speed \\ drops below the threshold speed \\ $N_{\mathrm{s}} \quad 15$ min bin \\ $T_{\mathrm{S}} \quad$ threshold speed, the average space mean speed \\ determined between 0200 and $0600 \mathrm{~h}$ \\ $v_{\mathrm{s}} \quad$ space mean speed
}

\section{Introduction}

Risk-based infrastructure management involves identifying, assessing and minimising unacceptable risk in the hopes of ensuring a desired level of performance or outcome. Assessing risk involves the implementation of measurable performance indicators (Carhart et al., 2016; Dolan et al., 2016). The risks to bridge structures can be due to extreme events, such as earthquakes, hurricanes, tornados and tsunamis, or involve catastrophic failure. The consequences of these types of events include the loss of life, money and mobility. There is also a risk associated with an asset performing improperly, which generally involves the loss of money (Proctor and Varma, 2012). For example, it was estimated that in the British, French, German and US economies over $\$ 200$ billion were lost due to traffic congestion in 2013. This number is expected to rise to US\$300 billion by 2030 (Anon, 2014).

Bridge structures are designed for strength and serviceability over their design life. The strength component ensures that the bridge will not experience structural failure. Serviceability is meant to ensure that the structure can carry the required type and number of vehicles at the appropriate design speed. A bridge must perform well in each of these areas for it to be economically viable. There exist many forms of strength assessment for bridge structures ranging from visual inspection to proof loading. In the case of proof loading, a known load is applied to a bridge, and its response is directly measured. The serviceability in bridge structures has historically been evaluated indirectly using roadway geometry and average daily traffic (ADT). This indicates how, despite generally being managed separately, bridges are part of the transportation network. The roadway geometry that differs from the base condition theoretically reduces the calculated freeflow speed (National Research Council, 2016). In the presence of other vehicles, this reduction in the level of service for the bridge can be classified as congestion. The presence of congestion is an indicator of poor serviceability. However, conditions that in theory can result in congestion do not always produce congestion. Therefore, where the NBI might theoretically indicate the presence of congestions, once measured in the field, it may not be the case.

In the past, it had not been economically feasible to directly measure and quantify congestion. With the recent development of regionally dispersed commercially available anonymous probevehicle speed data, it is becoming possible to spatially and temporally evaluate congestion occurrence (Brennan et al., 2014). Recent studies have applied performance measures based on these data to evaluate bridges, highway corridors, crash incidents and construction projects (Bechtel et al., 2015; Brennan et al., 2015; Lomax et al., 2011, 2012; Remias et al., 2012, 2013). 
This paper presents an evaluation of 2211 bridges regionally dispersed in the state of New Jersey using a yearly congestion metric calculated from crowdsourced anonymous probe-vehicle data. The main goal of the work is to evaluate the yearly congestion metric as a performance indicator for bridge service that can be incorporated into bridge asset management strategies. The congestion metric is compared to the performance designation found in the US National Bridge Inventory (NBI). These performance designations evaluate bridge service using bridge and roadway geometry as well as ADT. The yearly congestion metric is then incorporated into a rudimentary management scheme to evaluate how the decision-making process changes using congestion performance measures.

\section{NBI}

The NBI is a comprehensive database containing information on the bridge structures in the US; it is openly available for anyone (FHWA, 2017). The NBI items are based on information from physical bridge inspections. The intent of the database is to represent the performance of bridges at a national level in a comparable way. The NBI contains a rating system with two performance designations: structurally deficient (SD) and functionally obsolete (FO). Structural deficiency is based on structural evaluations of the bridge's deck, super structure and substructure. The structural evaluation is based on the minimum capacity found between the deck, superstructure and substructure. The waterway adequacy is a comparison of the deck elevation and the elevation of a 100-year flood. A bridge is considered SD if any of the conditions shown in Table 1 are met. Likewise, a bridge is categorised as FO if any of the conditions in Table 2 are met. Based on NBI standards, structural deficiency supersedes functional obsolescence or, in other words, the risk of structural inadequacy outweighs the risk due to poor service. A bridge found to be FO may be due to low scores in the structural evaluation (S) or under clearances (U), which obstruct large heavy vehicles, requiring them to choose an alternate route. These types of obstructions will only minimally interfere in the daily flow of

Table 1. SD NBI scoring categories (FHWA, 1995)

\begin{tabular}{|lcc|}
\hline Category & NBI item number & Deficiency score \\
\hline Deck condition & 58 & $\leq 4$ \\
Superstructure & 59 & $\leq 4$ \\
Substructure & 60 & $\leq 4$ \\
Structural evaluation & 67 & $\leq 2$ \\
Waterway adequacy & 71 & $\leq 2$
\end{tabular}

traffic for the average passenger vehicle when compared over an entire year. Bridges classified as FO due to deck geometry (D), approach roadway alignment (A) or waterway adequacy (W) have geometries or obstructions that cause a reduction in speed.

A bridge determined to have poor deck geometry (D) does not have an adequate width or number of lanes to accommodate the ADT. A bridge with poor roadway alignment (A) is expected to require a speed reduction upon approach to improve throughput. A bridge with poor waterway adequacy (W) frequently floods, making it impassable during certain periods. Poor deck geometry can also be a function of insufficient under clearance (U). All these conditions, except lack of under clearance, are expected to result in a reduction in speed that can lead to congestion. Subsequently, improving these areas will help mitigate the risk of poor performance. An analysis of the 1992 NBI showed that the single leading cause for deficiency (including both SD and FO) was deck geometry (Dunker and Rabbat, 1995).

The designations in the NBI seek to mitigate poor performance. While the rating factors for deck geometry, road alignment and, to some extent, waterway adequacy are meant to represent areas where congestion might occur, they are in themselves not measures of congestion. The NBI uses ADT and bridge and roadway geometries to model conditions where congestion is likely.

\section{New Jersey NBI data}

The state of New Jersey serves as an excellent test bed for the evaluation of serviceability using congestion metrics. It is located on the eastern seaboard of the USA and has the highest population density of the 50 states. It is positioned between the first (New York, New York) and fifth (Philadelphia, Pennsylvania) most populated cities in the USA, as shown in Figure 1(a). The state of New Jersey is divided into 21 counties, which can be viewed in Figure 1(b). Within the state 6609 bridges were reported in the 2014 NBI. Of the 6609 bridges, 621 can be classified as SD and 1723 can be classified as FO. Consistent with the findings of Dunker and Rabbat (1995), an evaluation of the 2014 NBI data revealed that $62 \%$ of the bridges classified as FO and $44 \%$ of bridges classified as SD have deck rating less than or equal to 3 . These structures should theoretically be causing congestion. Table 3 contains the total number of bridges as well as the number and per cent of SD and FO bridges within each county. Of the 21 counties, 16 have a total percentage of deficient bridge structures (Table 3) greater than the national average of approximately 25\% (ASCE, 2013). Essex County has the highest

Table 2. FO NBI scoring categories (FHWA, 1995)

\begin{tabular}{llc} 
Category & \multicolumn{1}{c}{ Description } & NBI item number \\
Structural evaluation (S) & Capacity evaluation & 67 \\
Waterway adequacy (W) & Flood evaluation & 71 \\
Deck geometry (D) & Bridge width against ADT and number of lanes & $\leq 3$ \\
Under clearances (U) & Height over roadway beneath & 68 \\
Approach roadway alignment (A) & Angle between bridge and approach & 69 \\
\hline
\end{tabular}


Infrastructure Asset Management

Volume 5 issue 3
Using anonymous probe-vehicle data for

a performance indicator of bridge service

Bechtel, Brennan, Gurski and Ansley

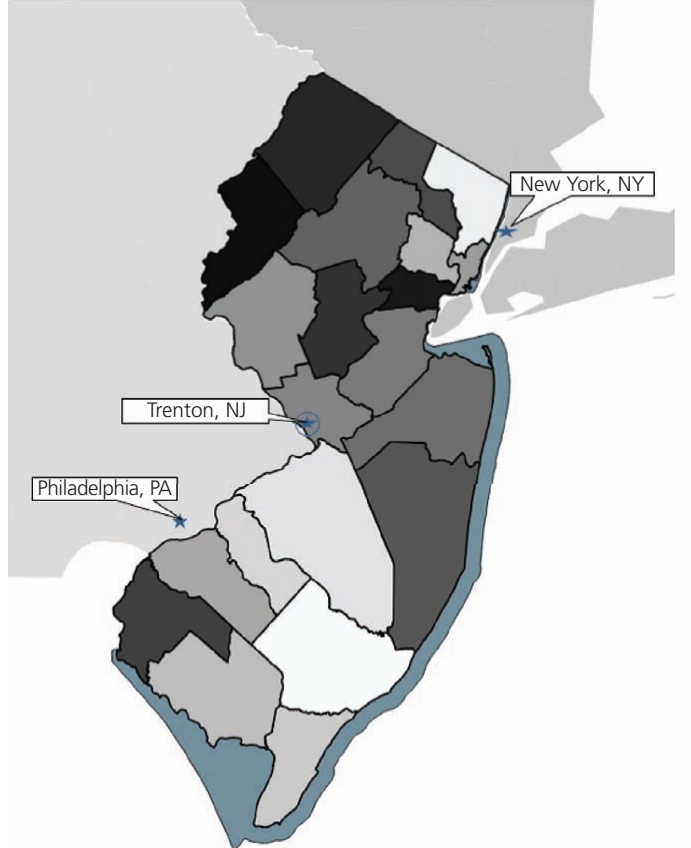

(a)

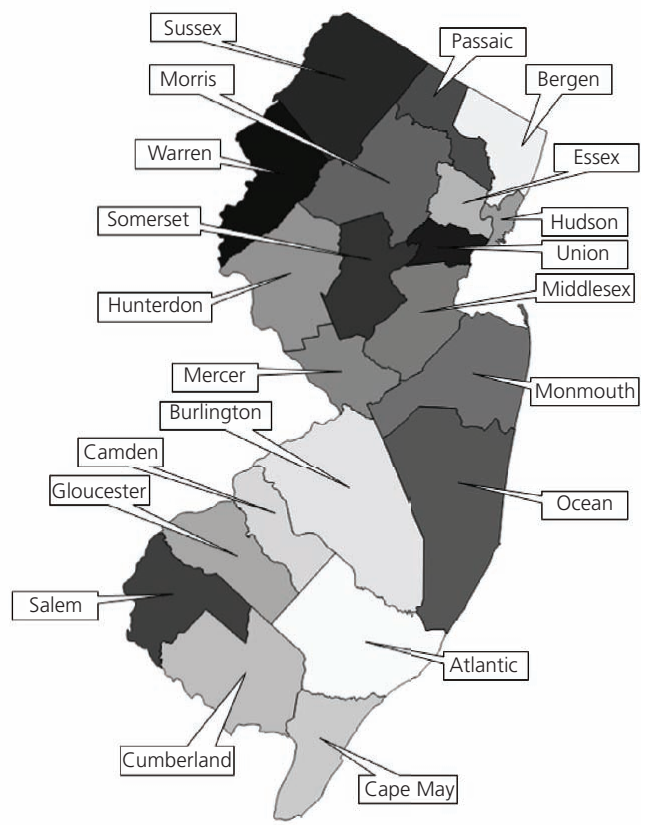

(b)

Figure 1. (a) State of New Jersey and (b) counties of New Jersey

Table 3. Deficient bridges per county in New Jersey

\begin{tabular}{|c|c|c|c|c|c|c|}
\hline \multirow{2}{*}{ County } & \multirow{2}{*}{ Bridges } & \multicolumn{2}{|c|}{ SD } & \multicolumn{2}{|c|}{ FO } & \multirow{2}{*}{ Total per cent deficien } \\
\hline & & Number & Per cent & Number & Per cent & \\
\hline Atlantic & 200 & 27 & $13 \cdot 50$ & 47 & $23 \cdot 50$ & $37 \cdot 00$ \\
\hline Bergen & 553 & 49 & 8.86 & 194 & 35.08 & $43 \cdot 94$ \\
\hline Burlington & 341 & 38 & $11 \cdot 14$ & 87 & $25 \cdot 51$ & $36 \cdot 66$ \\
\hline Camden & 250 & 24 & $9 \cdot 60$ & 71 & $28 \cdot 40$ & 38.00 \\
\hline Cape May & 64 & 7 & $10 \cdot 94$ & 6 & $9 \cdot 38$ & $20 \cdot 31$ \\
\hline Essex & 497 & 36 & $7 \cdot 24$ & 207 & 41.65 & 48.89 \\
\hline Gloucester & 242 & 15 & $6 \cdot 20$ & 36 & $14 \cdot 88$ & 21.07 \\
\hline Hudson & 184 & 18 & $9 \cdot 78$ & 68 & $36 \cdot 96$ & $46 \cdot 74$ \\
\hline Hunterdon & 365 & 47 & $12 \cdot 88$ & 93 & $25 \cdot 48$ & $38 \cdot 36$ \\
\hline Mercer & 370 & 59 & $15 \cdot 95$ & 68 & $18 \cdot 38$ & $34 \cdot 32$ \\
\hline Middlesex & 547 & 32 & $5 \cdot 85$ & 138 & $25 \cdot 23$ & 31.08 \\
\hline Monmouth & 500 & 65 & 13.00 & 150 & $30 \cdot 00$ & 43.00 \\
\hline Ocean & 237 & 15 & $6 \cdot 33$ & 41 & $17 \cdot 30$ & $23 \cdot 63$ \\
\hline Passaic & 327 & 22 & $6 \cdot 73$ & 101 & $30 \cdot 89$ & $37 \cdot 61$ \\
\hline Salem & 112 & 10 & 8.93 & 17 & 14.29 & $24 \cdot 11$ \\
\hline Somerset & 387 & 33 & $8 \cdot 53$ & 74 & $19 \cdot 12$ & $27 \cdot 65$ \\
\hline Sussex & 172 & 28 & $16 \cdot 28$ & 36 & $20 \cdot 93$ & $37 \cdot 21$ \\
\hline Union & 402 & 22 & $5 \cdot 47$ & 110 & $27 \cdot 36$ & $32 \cdot 84$ \\
\hline Warren & 256 & 30 & $11 \cdot 72$ & 54 & 21.09 & $32 \cdot 81$ \\
\hline
\end{tabular}

percentage of deficient bridges, and it is tied with Bergen County for the most deficient bridges.

Table 4 organises the bridges by owner. Of the 6609 bridges in the state of New Jersey, approximately $36 \%$ are owned by the State Highway Agency, 39\% are owned by the County Highway
Agency, $17 \%$ are owned by the State Toll Authority, $1 \%$ are owned by the local municipalities and the final $7 \%$ are owned by other agencies such as airport services and local toll authorities. The state of New Jersey, followed closely by its counties, owns the most deficient bridges in total. A greater percentage of bridges owned by other agencies are considered deficient. 
Table 4. SD and FO bridges owned per agency

\begin{tabular}{|c|c|c|c|c|c|c|}
\hline \multirow{2}{*}{ Owner } & \multirow{2}{*}{ Total bridges } & \multicolumn{2}{|c|}{ SD } & \multicolumn{2}{|c|}{ FO } & \multirow{2}{*}{ Total per cent deficient } \\
\hline & & Number & Per cent & Number & Per cent & \\
\hline State highway agency & 2370 & 232 & $9 \cdot 79$ & 560 & $23 \cdot 63$ & $33 \cdot 4$ \\
\hline County highway agency & 2589 & 277 & $10 \cdot 70$ & 512 & $19 \cdot 78$ & $30 \cdot 5$ \\
\hline State toll authority & 1145 & 16 & $1 \cdot 40$ & 455 & $39 \cdot 74$ & $41 \cdot 1$ \\
\hline Local municipalities & 86 & 5 & $5 \cdot 81$ & 18 & $20 \cdot 93$ & $26 \cdot 8$ \\
\hline Others & 419 & 91 & $21 \cdot 72$ & 177 & $42 \cdot 24$ & $64 \cdot 0$ \\
\hline
\end{tabular}

\section{Determination of congestion metric}

In order for a bridge's congestion to be evaluated using probevehicle data, it must be located adjacent to a traffic message channel (TMC). Of the 6609 bridges in the state of New Jersey, 2211 contain TMCs that span the structure. Only structures currently adjacent to TMCs were included in the current study. It is possible to request the addition of TMC segments, making the process explored in this study applicable to all bridges. The number of bridges with adjacent TMCs located in each county is given in Table 5. Table 5 also gives the number of bridges having SD and FO service designations. Half of these bridges are considered deficient due to deck geometry and ADT. Table 6 contains the number of SD and FO bridges owned by each agency located adjacent to a TMC. Figure 2 gives a visual comparison between the total numbers of $\mathrm{SD}$ and FO bridges located in the state of New Jersey compared to those that were analysed. The legend in Figure 2 gives the number of bridges in each category.

Commercially available crowdsourced anonymous probe-vehicle data was used to determine the congestion at bridge structures. These data are composed of timestamped speed data calculated in $1 \mathrm{~min}$ intervals for each TMC. The temporally and spatially defined speed data are derived from GPS signals. A timestamp is

Table 5. Deficient bridges per county in New Jersey with TMCs

\begin{tabular}{|c|c|c|c|c|c|c|}
\hline \multirow{2}{*}{ County } & \multirow{2}{*}{ Bridges } & \multicolumn{2}{|c|}{ SD } & \multicolumn{2}{|c|}{ FO } & \multirow{2}{*}{ Total per cent deficient } \\
\hline & & Number & Per cent & Number & Per cent & \\
\hline Atlantic & 48 & 6 & $12 \cdot 50$ & 15 & $31 \cdot 25$ & $43 \cdot 75$ \\
\hline Bergen & 208 & 21 & $10 \cdot 10$ & 82 & $39 \cdot 42$ & $49 \cdot 52$ \\
\hline Burlington & 151 & 16 & $10 \cdot 60$ & 49 & $32 \cdot 45$ & 43.05 \\
\hline Camden & 132 & 13 & $9 \cdot 85$ & 40 & $30 \cdot 30$ & $40 \cdot 15$ \\
\hline Cape May & 19 & 1 & $5 \cdot 26$ & 0 & 0.00 & $5 \cdot 26$ \\
\hline Cumberland & 33 & 5 & $15 \cdot 15$ & 2 & 6.06 & $21 \cdot 21$ \\
\hline Essex & 153 & 16 & $10 \cdot 46$ & 66 & $43 \cdot 14$ & $53 \cdot 59$ \\
\hline Gloucester & 110 & 8 & $7 \cdot 27$ & 20 & $18 \cdot 18$ & $25 \cdot 45$ \\
\hline Hudson & 75 & 9 & $12 \cdot 00$ & 27 & 36.00 & 48.00 \\
\hline Hunterdon & 83 & 13 & $15 \cdot 66$ & 10 & $12 \cdot 05$ & $27 \cdot 71$ \\
\hline Mercer & 154 & 24 & $15 \cdot 58$ & 33 & $21 \cdot 43$ & $37 \cdot 01$ \\
\hline Middlesex & 201 & 18 & 8.96 & 66 & $32 \cdot 84$ & $41 \cdot 79$ \\
\hline Monmouth & 153 & 25 & $16 \cdot 34$ & 52 & 33.99 & $50 \cdot 33$ \\
\hline Morris & 154 & 10 & $6 \cdot 49$ & 45 & $29 \cdot 22$ & $35 \cdot 71$ \\
\hline Ocean & 67 & 9 & $13 \cdot 43$ & 12 & $17 \cdot 91$ & $31 \cdot 34$ \\
\hline Passaic & 138 & 11 & $7 \cdot 97$ & 51 & 36.96 & 44.93 \\
\hline Salem & 34 & 2 & $5 \cdot 88$ & 10 & $29 \cdot 41$ & $35 \cdot 29$ \\
\hline Somerset & 108 & 10 & $9 \cdot 26$ & 22 & $20 \cdot 37$ & $29 \cdot 63$ \\
\hline Sussex & 28 & 6 & $21 \cdot 43$ & 6 & $21 \cdot 43$ & $42 \cdot 86$ \\
\hline Union & 111 & 7 & $6 \cdot 31$ & 34 & $30 \cdot 63$ & 36.94 \\
\hline Warren & 51 & 13 & $25 \cdot 49$ & 13 & $25 \cdot 49$ & $50 \cdot 98$ \\
\hline
\end{tabular}

Table 6. Deficient bridges owned per agency with TMCs

\begin{tabular}{|c|c|c|c|c|c|c|}
\hline \multirow{2}{*}{ Owner } & \multirow{2}{*}{ Total bridges } & \multicolumn{2}{|c|}{ SD } & \multicolumn{2}{|c|}{ FO } & \multirow{2}{*}{ Total per cent deficient } \\
\hline & & Number & Per cent & Number & Per cent & \\
\hline State highway agency & 1211 & 135 & $11 \cdot 15$ & 314 & $25 \cdot 93$ & $37 \cdot 1$ \\
\hline County highway agency & 559 & 82 & $14 \cdot 67$ & 144 & $25 \cdot 76$ & $40 \cdot 4$ \\
\hline State toll authority & 326 & 5 & $1 \cdot 53$ & 145 & $44 \cdot 48$ & $46 \cdot 0$ \\
\hline Local municipalities & 11 & 1 & $9 \cdot 09$ & 3 & $27 \cdot 27$ & $36 \cdot 6$ \\
\hline Others & 104 & 20 & $19 \cdot 23$ & 49 & $47 \cdot 12$ & $66 \cdot 4$ \\
\hline
\end{tabular}


Infrastructure Asset Management Volume 5 Issue 3
Using anonymous probe-vehicle data for a performance indicator of bridge service Bechtel, Brennan, Gurski and Ansley

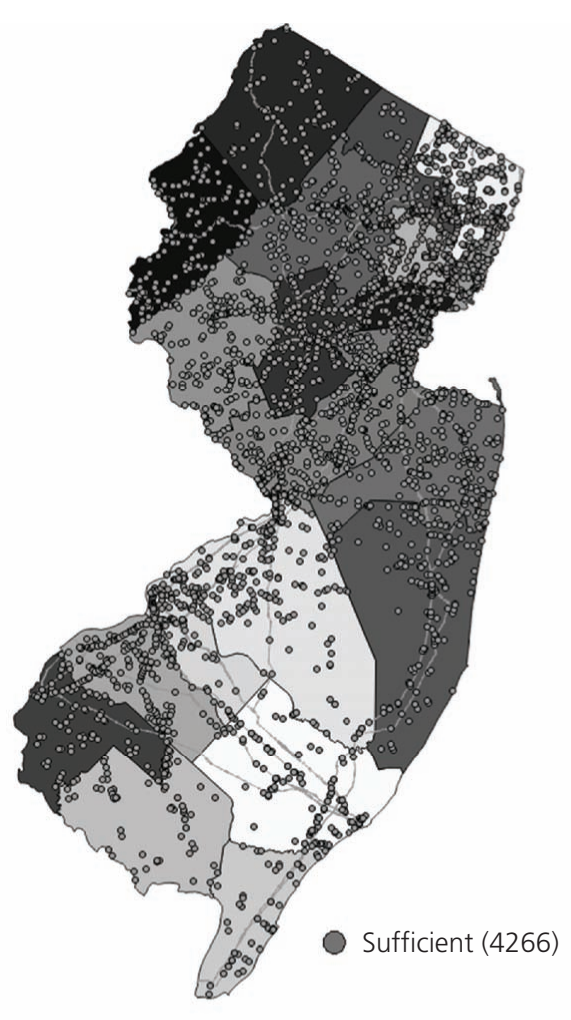

(a)

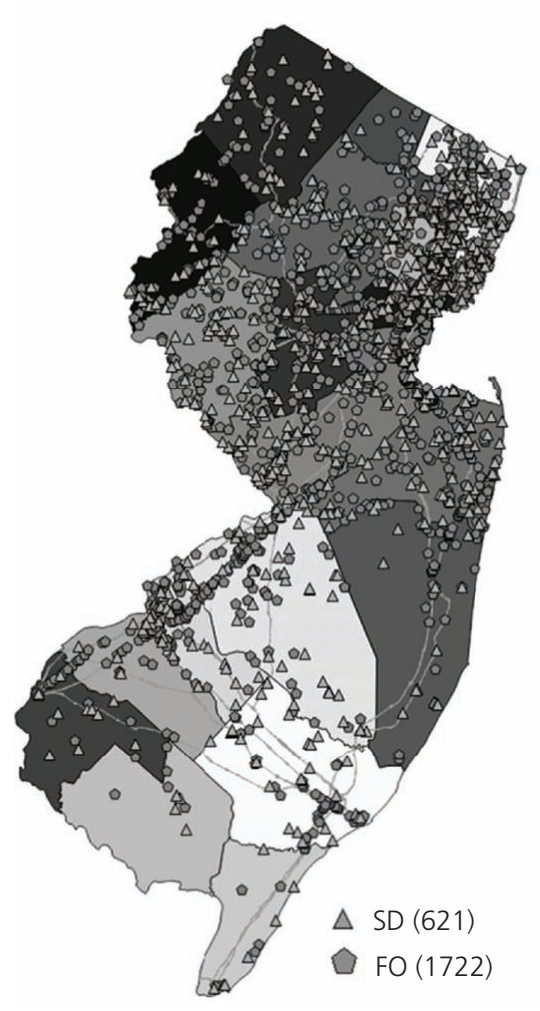

(c)

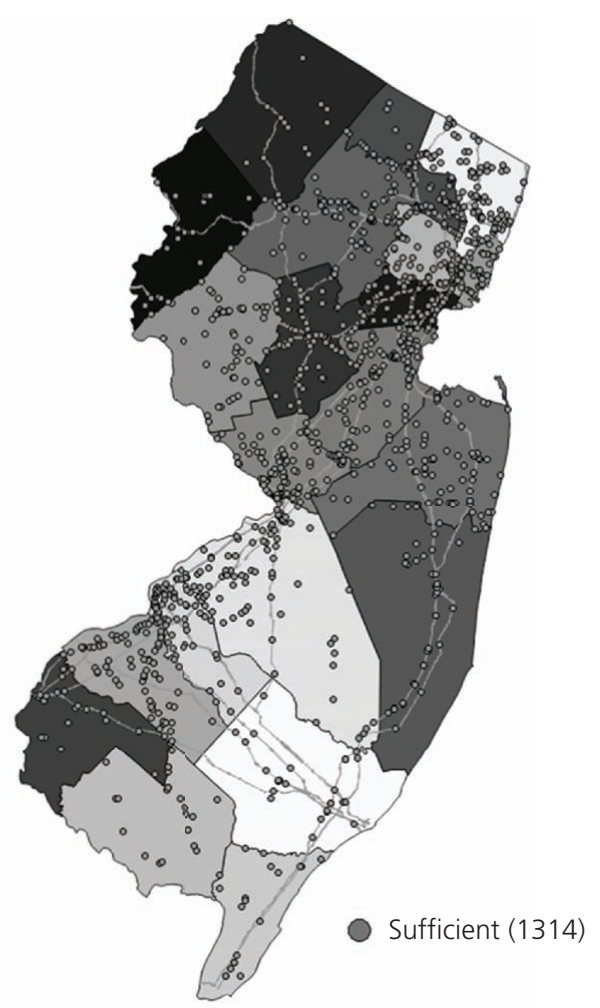

(b)

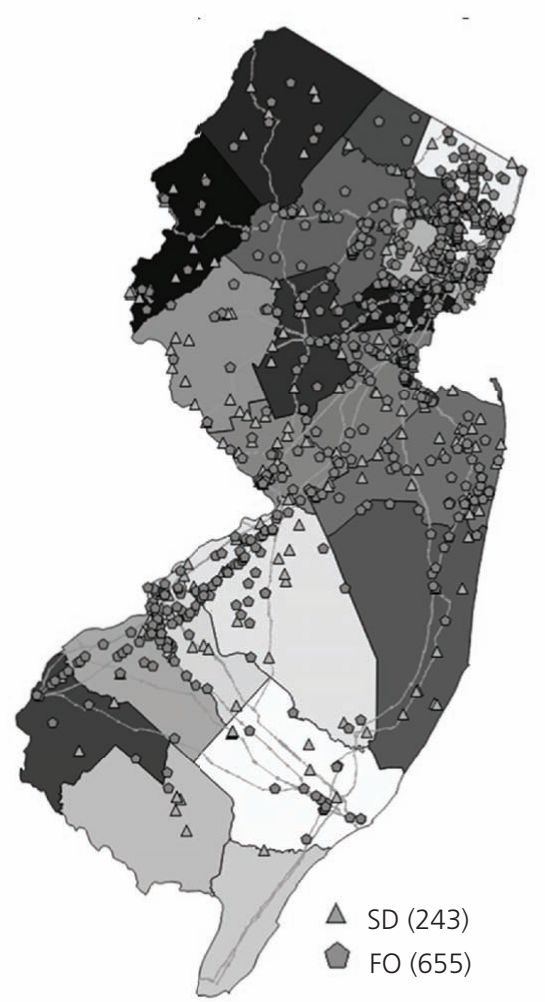

(d)

Figure 2. New Jersey bridges reported in 2014 NBI: (a) total sufficient bridges, (b) analysed sufficient bridges near TMC, (c) total deficient bridges and (d) analysed deficient bridges near TMC 
taken when a vehicle enters and leaves a TMC, and the difference in these timestamps gives the travel time along the TMC. An average speed is estimated by dividing the travel time by the length of the TMC. The averages are aggregated through a proprietary process and reported in $1 \mathrm{~min}$ increments. This study consisted of analysing approximately 2.4 billion speed records collected in 2014 for bridge structures in the state of New Jersey. The data were sorted into $15 \mathrm{~min}$ bins for each day of the year. Congestion is associated with a reduction in speed. For this study, congestion was assumed to occur when the speed dropped below a threshold speed. The threshold speed was calculated as the 70th percentile space mean speed (SMS) for each individual TMC, which was calculated using the average speed data between the hours 0200 and 0600 each day (Brennan et al., 2015). In order to determine congestion hours, each SMS was compared to the congestion threshold speed calculated for each TMC and assigned a binary indicator. If the SMS fell below the threshold, the $15 \mathrm{~min}$ bin was assigned a value of one; if it was above the speed value, it was assigned a value of zero. This relationship is defined in Equation 1. $C_{\mathrm{Hs}}$ is the count of the $15 \mathrm{~min}$ bins $\left(N_{\mathrm{s}}\right)$ for a particular segment, where $\operatorname{SMS}\left(v_{\mathrm{s}}\right)$ falls below the threshold speed $\left(T_{\mathrm{S}}\right)$ for the $15 \mathrm{~min}$ analysis period. The resulting values can then be summed and multiplied by 0.25 to calculate the congestion hours $\left(C_{\mathrm{H}}\right)$.

\section{1. $C_{\mathrm{Hs}}=0.25 \times \sum N_{\mathrm{s}} \quad\left[v_{\mathrm{s}}<T_{\mathrm{S}}\right]$}

The congestion hours for each TMC can then be grouped by hour, day, month or year. For this study, the $C_{\mathrm{Hs}}$ were aggregated into a yearly congestion metric. Once the numbers of bridges of concern have been reduced, the congestion hours can be visualised in different manners to evaluate the performance of individual bridges (Bechtel et al., 2015).

The yearly congestion metric provides one aggregated number, which indicates how often a drop in free-flow speed occurs. It does not indicate why the speed has dropped or if the bridge is the cause for the drop in speed. In this way, the congestion metric is limited. There are many reasons why the free-flow speed adjacent to a bridge structure can decrease (construction, accidents, speed restrictions during school hours, an overabundance of vehicles etc.). However, it is possible for a bridge to have a high congestion metric due to conditions unrelated to itself. It needs to be considered that in the transportation network, bridges represent one of the most expensive elements. A linear foot of a highway bridge costs approximately five times more than a highway road of the same width. Using the yearly congestion metric at bridge locations not only helps highlight places in the transportation network experiencing congestion, but also highlights areas not experiencing congestion. This same limitation can be applied to the metrics for service implemented into the NBI. For example, if a bridge is considered to have insufficient width, but its width matches the roadway conditions for 2 miles $(3.21 \mathrm{~km})$ in either direction, there is no benefit from just widening the bridge. Realistically, bridge service cannot ever be directly removed from the system behaviour of the transportation network.

\section{Comparison of congestion metric to NBI performance designations}

Figure 3 shows all of the analysed bridges with indicators scaled by the yearly congestion metric. The congestion metric does not necessarily indicate that the bridge is the cause of congestion: it is an indicator that there is a problem local to the bridge. Conversely, it is also shows that there is not a problem at a bridge. To determine if the bridge is causing the congestion, each bridge must be looked at on a case-by-case basis. The bridges were broken into five arbitrary categories, which run from $0-500$, 500-1000, 1000-2000, 2000-2500 and 2500-6500 h. An indicator that can be used to evaluate a significant number of congestion hours is the number of peak travel hours in a year. There are approximately six peak travel hours per day (7 a.m. -10 a.m. and 4 p.m. -7 p.m.) and approximately 258 workdays in a year. This gives about 1550 peak travel hours a year. Bridges approaching this value experience congestion every day during work commute periods. Many of the bridges with the highest yearly congestion metrics are located, as would be expected, close to New York City. From Figure 3(a), it can be seen that there are a number of sufficient bridges throughout the state with high yearly congestion metrics. Figure 4(b) shows that the SD bridges with high congestion metrics are mostly located near New York City and, to some extent, Philadelphia. FO bridges (Figure $4(\mathrm{c})$ ) congregate in the same areas as the SD bridges.

Table 7 organises the bridges by NBI service designation and yearly congestion metric. Based on the information found in the New Jersey 2014 NBI data, it is expected, for the bridges analysed, that $50 \%$ of the deficient bridges, both $\mathrm{SD}$ and FO, would experience congestion. The results in Table 7 show that only $30 \%$ of deficient bridges have congestion metrics over $500 \mathrm{~h}$. All SD bridges require consideration due to the risk associated with their strength, but FO bridges only pose a risk of poor performance. Based on the information found in the 2014 NBI, it is expected that 359 of the FO bridges analysed require consideration due to poor deck geometry and ADT. The ADT/ AADT, in New Jersey, is calculated over a $48 \mathrm{~h}$ period, while the congestion performance measures are calculated $365 \mathrm{~d}$ a year, $24 \mathrm{~h}$ a day. High vehicle volume may occur at bridges, but if it does not result in a reduction in speed, there is no issue with bridge function. Only 16 of these bridges experienced congestion metrics over $500 \mathrm{~h}$; that is $4 \%$ of what the FO service designation represents.

Figure 4 and Table 8 contain all 27 bridges that have congestion metrics over $2500 \mathrm{~h}$. Eleven of these 27 bridges were considered sufficient according to the NBI; it is noted that most of these bridges are owned by the State Highway Agency. The majority of 


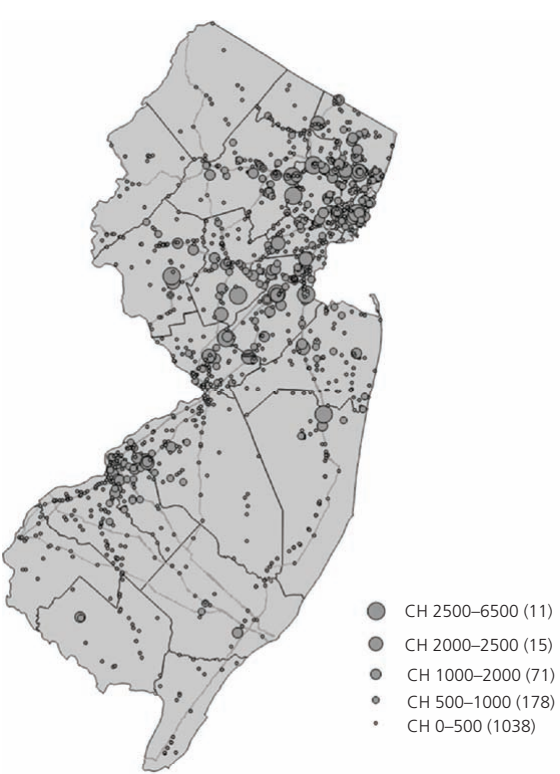

(a)

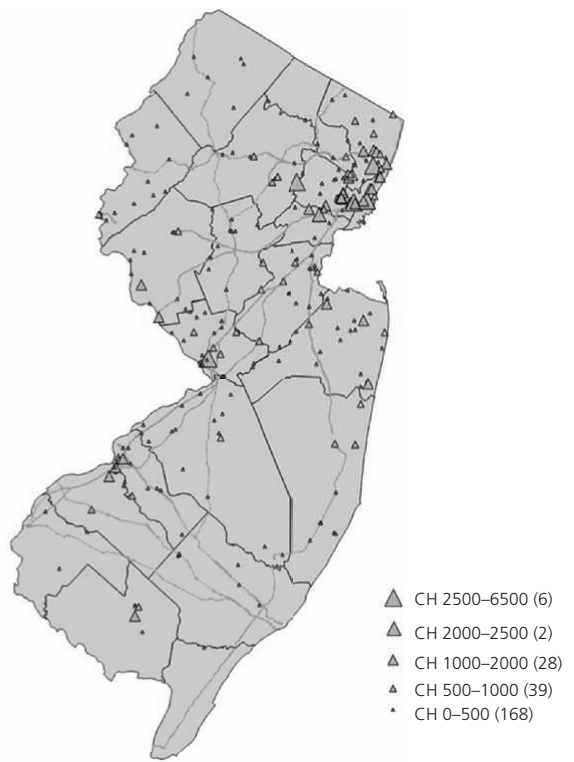

(b)

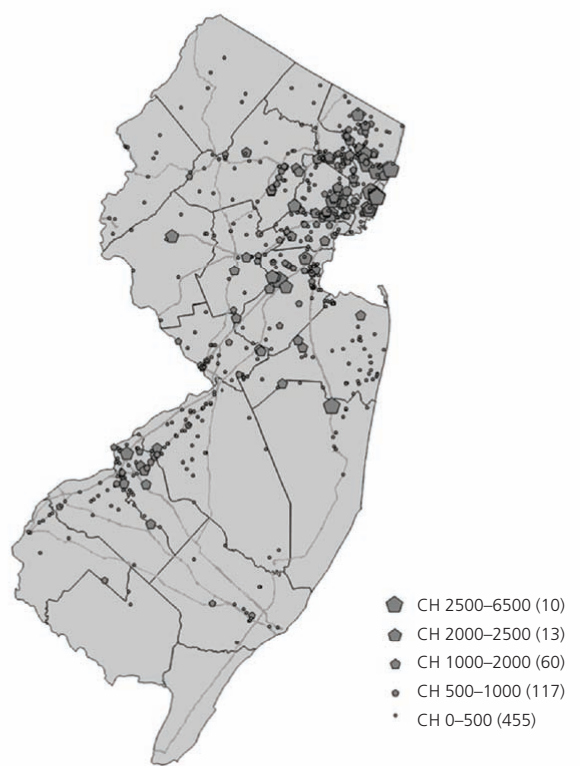

(c)

Figure 3. Bridges scaled by yearly congestion metric: (a) sufficient bridges scaled by congestion metric, (b) SD bridges scaled by congestion metric and (c) FO bridges scaled by congestion metric

these bridges are located in Hudson County, which is adjacent to New York City. However, not all bridges were located near major metropolitan areas. There were bridges in Hunterdon and Ocean Counties that were both considered sufficient yet experienced congestion metrics over $2700 \mathrm{~h}$. The ages of these bridges range from four to 100 years old, yet the average age of the bridges experiencing congestion metrics over $2500 \mathrm{~h}$ is 62 . The two bridges with the highest congestion metrics are bridges 904151 and 901150. These bridges are a part of the Pulaski Skyway (Figure 4), which was under construction during the time analysed.
Table 9 categorises bridges by yearly congestion metric and county, while Table 10 categorises them by yearly congestion metric and owner. Hudson County contains nine bridges with congestion metrics in excess of $2500 \mathrm{~h}$ with the next highest being Bergen County. When looking at the data from the NBI, Bergen and Essex Counties were tied for the highest number of deficient (both FO and SD) bridges. Hudson County was well behind these counties in the number of deficient bridges, yet it experiences a large amount of congestion hours. If a general conclusion about bridge deficiency were made from the NBI, then 


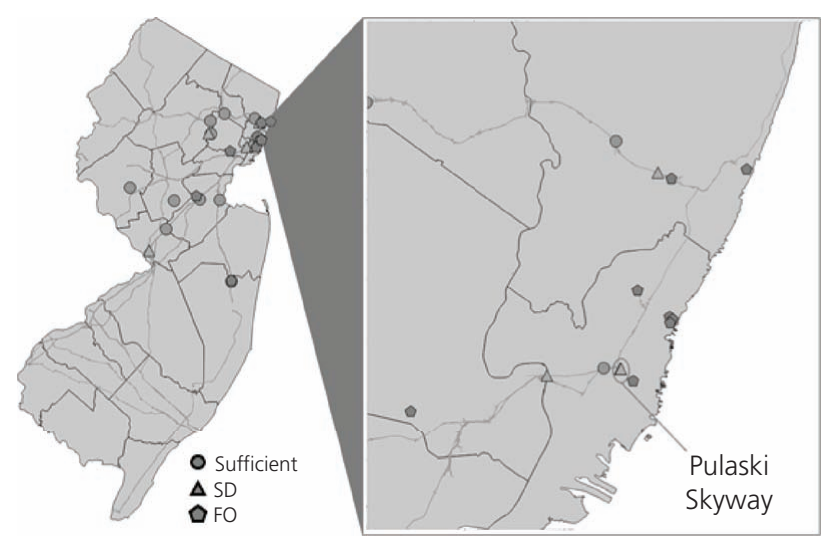

Figure 4. Bridges with yearly congestion metrics over $2500 \mathrm{~h}$

Essex and Bergen Counties would contain the most deficient bridges. Hudson County was found to have the highest number of bridges with large yearly congestion metrics. The State Highway
Agency owns the largest amount of bridges with high congestion metrics. Of the bridges analysed and owned by the State Highway Agency, $12 \%$ had congestion metrics over $1000 \mathrm{~h}$. This is double than that of the counties. Both the state and county agencies have approximately $26 \%$ of their bridges categorised, as FO (Table 6), but congestion is a larger problem for bridges owned by the state.

\section{Implementation of congestion metric in a management strategy}

In order to evaluate the usefulness of the congestion metric, a rudimentary bridge management strategy was implemented. The structural rating (NBI item 67) was used to represent the risk of structural failure while deck geometry (NBI item 68) was compared to the yearly congestion metric. The bridge length was incorporated to introduce a simple indication of cost. In the NBI, structural rating and deck geometry are ranked from zero to nine and are used to characterise a bridge's structural capacity and traffic capacity as a function of its ADT (FHWA, 1995). Figure 5 shows all the evaluated bridges in the state of New Jersey plotted by their structural and deck geometry appraisal rating factors as

Table 7. Bridges categorised by sufficiency and congestion hours

\begin{tabular}{lccrrr} 
& \multicolumn{4}{c}{ Bridge at each congestion hours } \\
\cline { 2 - 5 } Category & $2500-6500$ & $2000-2500$ & $1000-2000$ & $500-1000$ & 178 \\
Sufficient & 11 & 15 & 28 & 39 & 1038 \\
SD & 6 & 2 & 60 & 168 \\
FO & 10 & 13 & 455
\end{tabular}

Table 8. Bridges with yearly congestion metrics over $2500 \mathrm{~h}$

\begin{tabular}{|c|c|c|c|c|c|c|}
\hline Structure & County & Owner & Facility carried & Year built & Status & Congestion metric: $\mathbf{h}$ \\
\hline 904151 & Hudson & State highway agency & NJ 139 & 1927 & SD & $6226 \cdot 75$ \\
\hline 901150 & Hudson & State highway agency & U.S. $1+9$ & 1932 & SD & $6222 \cdot 00$ \\
\hline 3800029 & Hudson & Other state agencies & NJ-495 WB & 1954 & $\mathrm{FO}$ & $3963 \cdot 50$ \\
\hline 906161 & Hudson & State highway agency & US 1\&9T Ramp B & 2011 & Sufficient & $3851 \cdot 25$ \\
\hline 1504151 & Ocean & State highway agency & US Route 9 & 1908 & Sufficient & $3815 \cdot 75$ \\
\hline 3800027 & Hudson & Other state agencies & NJ-495 & 1937 & FO & $3659 \cdot 50$ \\
\hline 1410157 & Morris & State highway agency & Route US 46 & 1940 & Sufficient & $3552 \cdot 75$ \\
\hline 1514007 & Ocean & County highway agency & County Route 528 & 1987 & FO & 3538.00 \\
\hline 1402153 & Morris & State highway agency & NJ Route 10 & 1931 & SD & $3204 \cdot 25$ \\
\hline 709150 & Essex & State highway agency & NJ 10 & 1959 & Sufficient & $3192 \cdot 50$ \\
\hline 18G0404 & Somerset & County highway agency & Blackwellsmills Rd & 1994 & Sufficient & $3136 \cdot 00$ \\
\hline 1208150 & Middlesex & State highway agency & US 9 NB and NJ 35 & 1936 & Sufficient & $3107 \cdot 50$ \\
\hline 1604158 & Passaic & State highway agency & NJ Route 23 SBND & 1967 & Sufficient & $2962 \cdot 50$ \\
\hline 904154 & Hudson & State highway agency & NJ 139 WB & 1950 & FO & $2889 \cdot 00$ \\
\hline 1213154 & Middlesex & State highway agency & Route NJ 18 SB & 1988 & Sufficient & $2854 \cdot 00$ \\
\hline 1012154 & Hunterdon & State highway agency & RT31 & 2005 & Sufficient & $2732 \cdot 00$ \\
\hline 723151 & Essex & State highway agency & Lyons Avenue & 1976 & FO & $2709 \cdot 50$ \\
\hline 1217150 & Middlesex & State highway agency & NJ 27 & 1895 & FO & $2659 \cdot 75$ \\
\hline 904152 & Hudson & State highway agency & RT 139 EB Upper & 1927 & SD & $2633 \cdot 75$ \\
\hline 1103155 & Mercer & State highway agency & Route US 1 & 2010 & Sufficient & $2604 \cdot 00$ \\
\hline 221155 & Bergen & State highway agency & US 46 & 1934 & SD & $2593 \cdot 25$ \\
\hline 3800016 & Bergen & State toll authority & $1-95$ & 1930 & FO & $2580 \cdot 00$ \\
\hline 1100057 & Mercer & County highway agency & Nottingham Way & 1922 & SD & $2577 \cdot 75$ \\
\hline 213151 & Bergen & State highway agency & Terrace Ave. (CR 55) & 1988 & Sufficient & $2543 \cdot 00$ \\
\hline 3800026 & Hudson & Other state agencies & NJ-495 & 1937 & FO & $2542 \cdot 50$ \\
\hline 221156 & Bergen & State highway agency & Route US46 & 1934 & FO & $2535 \cdot 25$ \\
\hline 908150 & Hudson & State highway agency & Paterson Plank Rd & 1952 & FO & $2527 \cdot 50$ \\
\hline
\end{tabular}


Table 9. Bridges categorised by yearly congestion metric and county

\begin{tabular}{|c|c|c|c|c|c|c|}
\hline \multirow{2}{*}{ County } & \multicolumn{5}{|c|}{ Bridges at each congestion metric level } & \multirow{2}{*}{ Total } \\
\hline & $2500-6500$ & $2000-2500$ & 1000-2000 & $500-1000$ & $0-500$ & \\
\hline Atlantic & 0 & 0 & 1 & 4 & 43 & 48 \\
\hline Bergen & 4 & 6 & 22 & 40 & 136 & 208 \\
\hline Burlington & 0 & 2 & 3 & 10 & 136 & 151 \\
\hline Camden & 0 & 1 & 15 & 27 & 89 & 132 \\
\hline Cape May & 0 & 0 & 0 & 0 & 19 & 19 \\
\hline Cumberland & 0 & 0 & 2 & 2 & 29 & 33 \\
\hline Essex & 2 & 2 & 23 & 34 & 92 & 153 \\
\hline Gloucester & 0 & 0 & 5 & 9 & 96 & 110 \\
\hline Hudson & 9 & 4 & 20 & 15 & 27 & 75 \\
\hline Hunterdon & 1 & 2 & 4 & 4 & 72 & 83 \\
\hline Mercer & 2 & 2 & 4 & 23 & 123 & 154 \\
\hline Middlesex & 3 & 4 & 17 & 40 & 137 & 201 \\
\hline Monmouth & 0 & 1 & 9 & 9 & 134 & 153 \\
\hline Morris & 2 & 1 & 10 & 35 & 106 & 154 \\
\hline Ocean & 2 & 0 & 1 & 7 & 57 & 67 \\
\hline Passaic & 1 & 1 & 12 & 31 & 93 & 138 \\
\hline Salem & 0 & 0 & 0 & 1 & 33 & 34 \\
\hline Somerset & 1 & 1 & 6 & 19 & 81 & 108 \\
\hline Sussex & 0 & 0 & 0 & 0 & 28 & 28 \\
\hline Union & 0 & 3 & 5 & 22 & 81 & 111 \\
\hline Warren & 0 & 0 & 0 & 2 & 49 & 51 \\
\hline
\end{tabular}

Table 10. Bridges categorised by yearly congestion metric and owner

\begin{tabular}{|c|c|c|c|c|c|c|}
\hline \multirow{2}{*}{ Owner } & \multicolumn{5}{|c|}{ Bridges at each congestion metric level } & \multirow{2}{*}{ Tota } \\
\hline & $2500-6500$ & $2000-2500$ & $1000-2000$ & $500-1000$ & $0-500$ & \\
\hline State highway agency & 20 & 17 & 108 & 211 & 855 & 1211 \\
\hline County highway agency & 3 & 5 & 28 & 63 & 460 & 559 \\
\hline State toll authority & 1 & 7 & 16 & 45 & 257 & 326 \\
\hline Local municipalities & 0 & 1 & 1 & 2 & 7 & 11 \\
\hline Others & 3 & 0 & 6 & 13 & 82 & 104 \\
\hline
\end{tabular}

defined in Table 11. The three different marks in Figure 5 represent bridge length as defined in Table 12 .

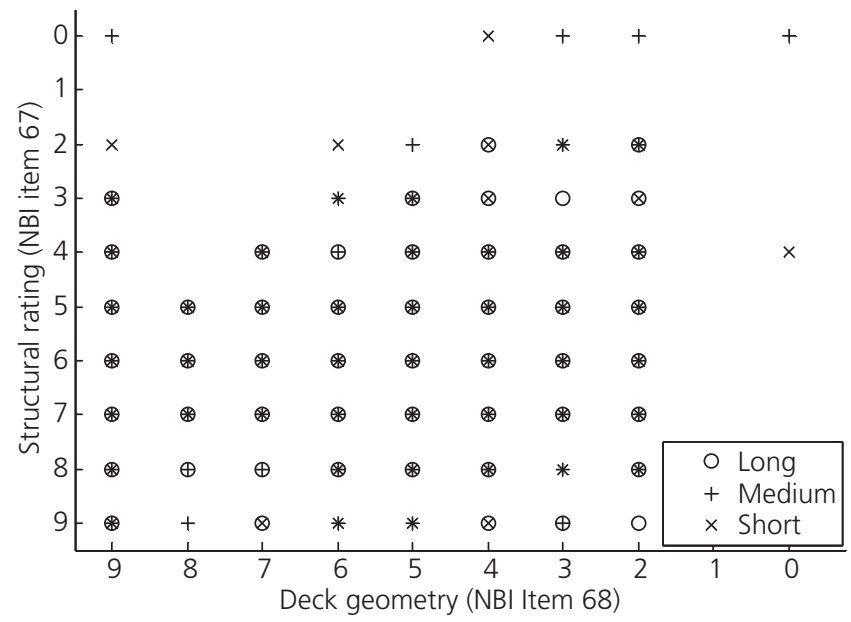

Figure 5. All evaluated bridges plotted by structural and deck geometry rating
Since the structural and deck geometry rating values are whole numbers, the results of plotting them are a grid (Figure 5). As demonstrated in Figure 5, multiple bridges occupy each spot on the grid. As the bridges move up the y-axis, their structural rating decreases, which means that the bridges at the top of the graph require more attention structurally. As the bridges move right along the $\mathrm{x}$-axis, their deck geometry rating decreases, which means that the bridges farthest to the right have inadequate deck

Table 11. NBI appraisal ratings (FHWA, 1995)

\begin{tabular}{ll} 
Code & \multicolumn{1}{c}{ Description } \\
\hline 9 & Superior to present desirable criteria \\
8 & Equal to present desirable criteria \\
7 & Better then present minimum criteria \\
6 & Equal to present minimum criteria \\
5 & Somewhat better than minimum adequacy to tolerate \\
4 & being left in place as is \\
3 & Meets minimum tolerable limits to be left in place as is \\
2 & Basically intolerable requiring high priority of corrective action \\
1 & Not used \\
0 & Bridge closed
\end{tabular}


Using anonymous probe-vehicle data for a performance indicator of bridge service Bechtel, Brennan, Gurski and Ansley
Table 12. Length classifications for bridges

\begin{tabular}{lc} 
Type & Length \\
\hline Short & $0-14 \mathrm{~m}(0-45 \mathrm{ft})$ \\
Medium & $14-46 \mathrm{~m}(45-150 \mathrm{ft})$ \\
Long & $46 \mathrm{~m}$ and up (150 ft and up)
\end{tabular}

geometry as a function of their ADT. One logical management strategy is to improve structural safety first and then improve service second. In Figure 5, there are five bridges with a structural rating of zero, and 18 bridges with a structural rating of two. Of these 23 bridges, 18 belong to county highway agencies; none of these bridges is owned by the state highway agency. Only four of these bridges are long-span bridges. These bridges should be closed unless they serve a purpose; in which case, they should be replaced. Additionally, four of these bridges are medium span and one is short span; these bridges are slated for replacement.

Figure 6 shows all evaluated bridges with a structural rating of three plotted by their deck geometry rating and length. There are 27 bridges with a structural rating of three. Five of these bridges have a deck geometry rating of two, which indicates that they are a high priority for replacement (A-E in Figure 6). Three of these bridges are long-span bridges, and two are short-span bridges. Two bridges are owned by the state, one by a county and two by other agencies.

Figure 7 shows a breakdown of the Figure 5 grid structure, where the bridges are plotted by structural rating and the yearly congestion metric. Figure 8 shows all bridges evaluated with a structural rating of three plotted by length and yearly congestion metric. The labels of the five bridges with a deck geometry rating of two are carried over from Figure 5. These bridges do not experience congestion metrics over $1000 \mathrm{~h}$. The bridge that experiences the highest congestion metric has a deck geometry

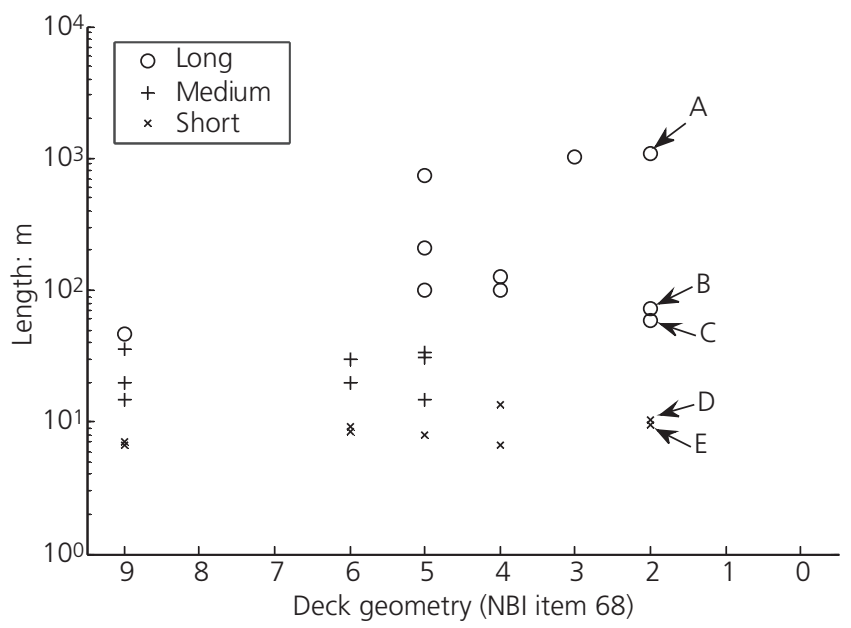

Figure 6. Bridges with a structural rating of three plotted by deck geometry rating and length

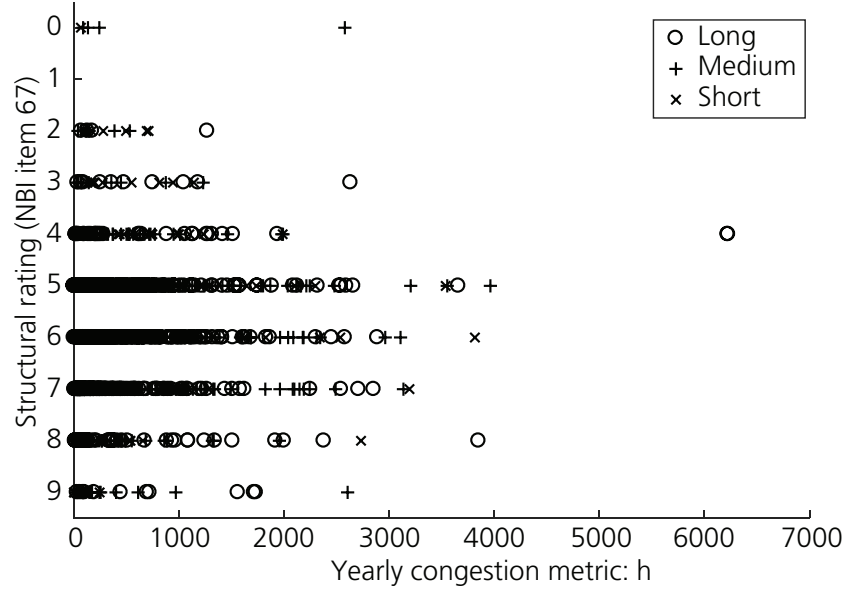

Figure 7. Bridges plotted by yearly congestion metric and deck geometry

rating of 3. Using the NBI ratings, five bridges, three of which are long span, would have been replaced before this bridge. When Figure 6 is compared to Figure 8, the benefits of the congestion metric become clear. For bridges with a high structural risk, it helps define the order which deficient bridge will be improved or replaced.

\section{Summary and conclusions}

Yearly congestion metrics based on anonymous probe-vehicle data were determined for 2211 bridges in the state of New Jersey. The analysis was performed at a large regional level without field evaluation. Without a field evaluation, the congestion metric cannot be directly tied to the bridge structure; it only indicates that the transportation system in the area is experiencing congestion. This congestion may or may not be caused by the bridge structure. When the yearly congestion metric was compared to the FO service designation found in the NBI, only

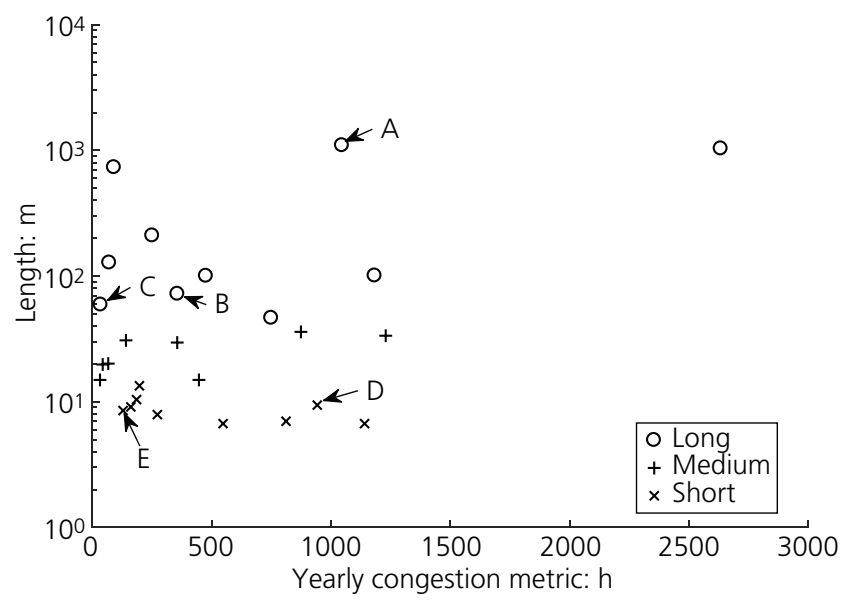

Figure 8. Bridges with a structural rating of three plotted by yearly congestion metric and length 
$4 \%$ of FO bridges analysed experienced congestion metrics over $500 \mathrm{~h}$ in 2014 . Only $55 \%$ of the bridges found to have yearly congestion metrics over $2500 \mathrm{~h}$ were identified as FO or SD in the 2014 NBI. Roadway conditions, which theoretically cause congestion, do not always cause congestion and vice versa. Higher congestion metrics were observed closer to large cities and on bridges owned by the state of New Jersey. When the yearly congestion was implemented in a rudimentary management strategy, it showed an advantage because it was a continuous yearly measurement as opposed to a rating number based on site conditions and a $48 \mathrm{~h}$ ADT collection.

The yearly congestion metric offers advantages over the FO service designation found in the NBI. The congestion metric serves as a measurement of what is happening in the state, while the NBI FO service designation relies on geometry and traffic counts to predict congestion conditions. Large congestion metrics do not indicate that the bridge itself is causing the congestion, but it identifies bridges with and without a local congestion issue. With the congestion issue identified, a proper analysis and engineering judgement can be used to make decisions about the structure and surrounding areas. Congestion hours can be aggregated and used in different ways to evaluate individual bridges as shown by Bechtel et al. (2015). As part of a risk-based assessment plan, congestion hours calculated from anonymous probe-vehicle data can be used as a tool to evaluate the service of a bridge or roadway. Minimising congestion hours will improve the overall performance and travel time reliability of an agency's transportation infrastructure. For these reasons, the yearly congestion metric has been found to be a valuable performance indicator. The next step in this research is to evaluate the cost of congestion for a motorist, which will make it possible to weigh the cost of an intervention against the benefit of improved service.

\section{REFERENCES}

Anon (2014) The Economist explains: the cost of traffic jams. The Economist, 3 November. See http://www.economist.com/blogs/ economist-explains/2014/11/economist-explains-1 (accessed 03/11/2014).
ASCE (American Society of Civil Engineers) (2013) Report Card for America's Infrastructure. ASCE, Reston, VA, USA. See http://www. infrastructurereportcard.org/bridges/ (accessed 07/09/2014).

Bechtel AJ, Brennan Jr TM and de Araujo JM (2015) Characterizing bridge functional obsolescence using congestion performance measures determined from anonymous probe-vehicle data. Journal of Performance of Constructed Facilities 30(2): 04015027.

Brennan TM, Day CM, Remias GM et al. (2014) Alternative performance measures and weighting for quantifying spatial and temporal congestion using probe data. Proceedings of the ITS 21st World Congress, ITSWC 2014: Reinventing Transportation in Our Connected World, Detroit, MI USA.

Brennan Jr TM, Remias SM and Manili L (2015) Performance measures to characterize corridor travel time delay based on probe-vehicle data. Transportation Research Record: Journal of the Transportation Research Board 2526: 39-50.

Carhart NJ, Bouch C, Walsh CL and Dolan T (2016) Applying a new concept for strategic performance indicators. Infrastructure Asset Management 3(4): 143-153, https://doi.org/jinam.16.00016.

Dolan T, Walsh CL, Bouch C and Carhart NJ (2016) A conceptual approach to strategic performance indicators. Infrastructure Asset Management 3(4): 132-142, https://doi.org/10.1680/jinam.16.00015.

Dunker KF and Rabbat BG (1995) Assessing infrastructure deficiencies: the case of highway bridges. Journal of Infrastructure Systems 1(2): $100-119$.

FHWA (Federal Highway Administration) (1995) Recording and Coding Guide for the Structure Inventory and Appraisal of the Nations, Bridges. Bridge Management Branch, Bridge Division, Washington, DC, USA.

FHWA (2017) Download NBI ASCII Files. FHWA, Washington, DC, USA. See https://www.fhwa.dot.gov/bridge/nbi/ascii.cfm (accessed 22/11/2017).

Lomax T, Shrank D and Eiselee B (2011) Urban Mobility Report Powered by INRIX Traffic Data. Texas A\&M Transportation Institute, College Station, TX, USA.

Lomax T, Shrank D and Eiselee B (2012) Urban Mobility Report Powered by INRIX Traffic Data. Texas A\&M Transportation Institute, College Station, TX, USA.

National Research Council (2016) Highway Capacity Manual (HCM) 2016. Transportation Research Board, Washington, DC, USA.

Proctor GD and Varma S (2012) Risk-based Transportation Asset Management Literature Review. FHWA, Washington, DC, USA, Report No. FHWA-HIF-12-036.

Remias S, Brennan T, Grimmer G et al. (2012) 2011 Indiana Interstate Mobility Report: Full Version. Purdue University, West Lafayette, IN, USA.

Remias SM, Brennan Jr TM, Day CM et al. (2013) 2012 Indiana Mobility Report: Full Version. Purdue University, West Lafayette, IN, USA.

\section{How can you contribute?}

To discuss this paper, please submit up to 500 words to the editor at journals@ice.org.uk. Your contribution will be forwarded to the author(s) for a reply and, if considered appropriate by the editorial board, it will be published as a discussion in a future issue of the journal. 